\title{
Language indexicalities in multilingual English language classrooms A narrative inquiry
}

\author{
Gambhir Bahadur Chand \\ Assistant Professor, Far Western University, Central Campus
}

\begin{abstract}
Language indexicality is the major problem in multilingual classrooms. Students from minority language communities may feel dominated in the classroom due to the lack of competency in the dominant languages used in the classroom. I have been dealing with such diversified classes for a long time and my teaching experience motivated me to carry out this research. This study tried to explore the nature of language dominance in a multilingual English language classroom and how students of minority community feel in the classroom. I used narrative inquiry as the main research design and purposive sampling procedure for sampling the participants and research site. Language dominance in the multilingual classroom was found problematic for minority community students. They mainly feel dominated in the classroom and do not enjoy studying in the classroom. The study also found that minority language learners are demotivated to take part in classroom interaction. Inappropriate use of dominating language by the teachers also found more problematic in the study. The study concluded that use of dominant language heavily in the multilingual classroom creates problem rather than helping those students who have different mother tongues.
\end{abstract}

Keywords: Dominant languages, hegemony, linguistic inferiority, minority languages, multilingual classroom

\section{Introduction}

Nepal is a multilingual, multiethnic and multicultural country where people of various cultures live together within a society. As such we do have multilingual and multi-cultural students in a classroom. Central Bureau of Statistics (2011) has stated that Nepal is a multilingual country with 123 languages. Each language has its own identity with its distinct culture. Each culture has its own norms and values and so are their understandings. Our community is mixed up with the people from these diverse cultures. School is the center where children gather and stretch with their learning. This shows that majority of the schools consists of students with different mother-tongues. Because of its geopolitical uniqueness, Nepal has become 
a place for multi-faceted research studies for the scholars from all over the world (Paudel, 2010). This richness, which is being faded due to the hegemony of dominant language(s), is needed to be preserved. For the preservation of language multiplicity, language policy of government and local arbiters (Johnson \& Johnson, 2015) such as local governments, teachers, students, curriculum designers, educationists, social workers and other concerned stake-holders are equally important. To preserve and promote multi-lingual, multi-ethnic society, classroom activities can play significant roles. For this, National Education Commission Report (1993) provisioned the policy of primary education in mother-tongue. But it does not seem much effective and meaningful as it was expected. Almost all private and some public schools choose English as the medium of instruction rather than their indigenous languages or any other mother-tongues. It is because they may have dominated feeling of their own language. This means if they use their mother tongue they may feel humiliation of being less standard. In the context of our country, we see there is contradiction between government policy regarding language and practice level. The constitution of Nepal 2015 clearly stated in Article 31 Section 5 that primary education from grade 1 to 3 should be in mother tongue (GoN, 2015). In practice, we could see some public schools have adopted English Medium Instruction (EMI). They have resisted the government's language policy and recreated their own language policy. This might be the result of position or image of a language in a society.

In Nepal, Nepali and English languages are taken as the dominant languages. The government of Nepal declared Nepali as an official language, and as a medium of instruction, English can be used at the secondary level to teach science and mathematics (GoN, 2015). From my long experience in teaching in multilingual classes both in private and public schools, it can be seen that private school teachers or students use either Nepali or English language while involving in classroom interaction or outside classroom.

Language is not just juxtaposition of words and sentences; it is the amalgam of culture, power, ideology, and identity (Hornberger \& Johnson, 2011). Language learning is also the process of learning culture of that language and that can be reproduced in users' behaviour. Therefore, a teacher in the classroom is also a user of a particular language. His/Her linguistic behaviour may affect the students whose language is different from teachers. This frequently happens in the multilingual classroom. Minority language group students may feel dominated and humiliated due to insufficient language proficiency. In that condition teacher should be very sensitive towards minority language groups in the classroom. Similarly, students 
whose mother tongue is used as the medium of instruction in the school or common with teachers' mother tongue they can build better rapport with teachers (Maum, 2002). They have more confidence and friendlier environment than those whose mother tongue is different from teachers. They can ask questions easily, can give reply easily and overall interaction can be more fruitful than others in the classroom. Observing these situations in multilingual classes, something used to strike me time and again saying that how do students feel and adjust whose mother tongue is not used as dominant language in the school? What sort of attitude do they possess towards dominant language? What is the effect of this kind of situation in language / learning in the classroom? Therefore, I want to explore how language indexicality influence language learning and classroom interaction of students as well as how linguistic hierarchies (Haberland \& Mortensen, 2012) are constructed and how power relations created by this hierarchy affects students' participation in language learning processes.

The main purpose of this study was to explore the nature of language dominance that the students from minority community feel and experience in multilingual English language classrooms. Further, it aimed at exploring how learners who speak L1 at home, L2 in the community and were learning English in the school respond to the use of dominant languages and how learning was influenced with dominant language use. This research was guided by the following questions such as: How do English language learners from minority community experience the use of dominant language(s) (English as dominant language) in English language classrooms? How do the students respond to the use of dominant languages while learning English? How do socio-cultural, ethnic and linguistic factors affect their participation in English language learning?

\section{Literature Review}

\section{Language dominance}

Language dominance is, on its face, a relatively simple concept. It refers to the degree of bilingualism manifested by individuals who know two languages, that is, the relative level of proficiency in each of the languages. A person may know both equally well, in which case we speak of balanced bilingualism. This term is also very common in multilingual society. A widely held assumption in bilingualism research is that bilinguals, rarely, if ever, demonstrate equal capacity in both of their languages, most likely as a result of the fact that they use their languages for different purposes, in different situations, and with different people (Grosjean, 2016; Treffers- 
Daller, 2019). In this way, we can say that a speaker who knows two or more than two languages does not speak all languages equally. The perception of user towards all languages may not have the same and they may use one language more than other. Birdsong (2014) states in the context of bilingual or multilingual society, one language dominates another language. It is also believed that a person cannot be equally competent in two languages and where one language has better position than others in an individual's performance (Xue \& Zuo, 2013). Why do people use a particular language more than others? Why do they prefer one language to another in their speech? Like this there are so many questions everybody raises in their mind. There are so many reasons why they prefer one language to another language. Among them language hegemony is the most important.

Simply, hegemony means dominance or supremacy. Gündoğan (2008) states that it was the term previously used by Marxist leaders (such as Vladimir Ilyich Lenin) and greatly expanded by Gramsci developing an acute analysis of how the ruling capitalist class establishes and maintains its control. The term 'hegemony' is derived from the Greek word meaning 'to lead'. It was conceptualized by the Italian political writer Antonio Gramsci (1891-1937). It is the power that one social group holds over others, with its military, cultural, and economical domination (Suarez, 2002). He further says that it is more than social power itself; it is a method for gaining and maintaining power. When people become mentally and materially less powerful or powerless, they will be defeated physically and mentally.

Each society has different social groups and every social group has superior and inferior groups, and so is in the school where children from all of the social groups gather to study. The superior group has dominant role, whereas the inferior group feels dominated because they are unable to maintain the standard that the superior group possesses. When the superior group rules over the inferior group within a society, the substandard group accepts the control believing that it is their consent and choice. Hegemony is found in every social context. Suarez (2002) claims that hegemony is a domination of a culturally diverse society by the ruling class via consent not by force where the ruling classes are the elite. The social practices of the elites become more influential than that of the substandard ones.

When a social group establishes their superiority through language use, power and behaviour, the other group which is unable to maintain it begins to feel inferior and then the superior group begins to dominate the inferior group through approval and persuasion. In the word of Gramsci (1971), it means intellectual and 
moral leadership through consent and persuasion. The dominant group always tries to show their superiority through different ways that are acceptable and right even in the view of inferior group. It is not physical coercion. It is related to the prestige connected with culture, economy, politics and social power. Suarez (2002) states, "Gramscian concept of hegemony is essentially comprised of three concomitant processes: leadership without force, leadership through legitimating and leadership through consensual rule" (p. 513). The superior group takes the leading role using ideas which are legally right and personally acceptable.

Generally, every society consists of two groups: the dominant group and subordinate group. Hegemony exists when the dominant group uses leadership without force which is a form of rule that uses consciousness rather than physical effort. The dominant group always legitimizes their leadership as a form of rule where the subordinate group views their control is right, justifiable and unquestionable. The dominant groups always exercise their leadership through consensual rule which is a form of rule that convinces the dominated group to believe that their inferior position is at their own choice and benefits them. Moreover, they think the needs and concerns of the superior group are mutual. Therefore, the dominant group always secures its superiority through the willingness and consent of the dominated group.

As every society consists of two classes: ruled class and ruling class and two levels of society: civil society and political society, the ruling class uses its power from these levels (civil society and political society) using different methods to persuade the substandard groups. Bates (2010) further states that civil society is the market place of ideas where intellectuals send their ideas in the market to sway the public opinion. This scenario with standard and sub-standard groups is clearly seen in classroom environment as well. The standard group secures the consent through the extension of their worldviews. They will flourish with their ideas in a discipline and tricky way to those who do not consent and move ahead. Thus, through the use power and social techniques isolating, ignoring and limiting supports to those who do not consent and appreciating, paying attention to their direct needs and providing supports to those who consent help to create hegemony. Invisible partiality becomes a key to influence other inferior ones. Hegemony is not only the part of linguistics but it can also spread through culture. 
Culture is the system of shared beliefs which are different from one social group to another. In other words, it is a way of life. Matsumoto (1996) defines culture as "the set of attitudes, values, beliefs, and behaviours shared by a group of people..." When the culture, which is dominant one, influences the inferior one, hegemony begins (cited in Spencer-Oatey, 2012, p.1). Similarly, Jiang (2011, p. 197) argues cultural hegemony as a means of the spontaneous consent given by the great masses of the population to the general direction imposed on social life by the dominant group the ruled class accepts the worldview of the ruling one as valid and acceptable cultural norms. When a group of the society believes that they are inferior and are unable to meet the standard of the elite group, hegemony is guaranteed. According to Wiley (as cited by Suarez, 2002, p. 513), "hegemony is ensured when they can convince those who fail to meet those standards to view their failure as being the result of the inadequacy of their own language." People think that without English, opportunities and accesses are completely limited. Then, they learn English with which they can flourish. When they have good English, they will have better and more opportunities, wider access and higher status. They are fully convinced that without English, opportunities, accesses and status are lessened.

\section{Development of English as a dominant language}

While talking about the history of language domination, we can find out different turning points of domination of different languages in different periods of time. For example, Latin became a common language throughout the Roman Empire. Similarly, Greek became an international language in the Middle East more than 2000 years ago. It is not because of the intellect of Plato and Aristotle but due to swords and spears. Furthermore, Arabic became a lingua franca across the Northern Africa and the middle East due to the force of Moorish armies from 18th century (Crystal, 2003). They rose up with popularity but could not remain stable because they spread only with power not with consensual rule and other factors to globalize them.

In the case of English, it became a dominant language because of its international position or being an international language. In the same way, English speaking countries became the destinations for the students of non-English speaking countries for their higher studies. It is the language for international communication, a language of opportunity and empowerment, a language of academic achievement, a medium of communication in tourism and trade and an access in science and technology (Crystal, 2003). In later days, everyone needs English to communicate 
with people across the culture and to compete for national and global opportunities. It is also a tool of access and power. Similarly, Xue and Zuo (2013) mention the following as the reasons of the formation of English dominance: "Power of the people who use it, close relationship with the vitality of the language itself, universalness of English, marketization and technical power of British and America and language of universal culture" (pp. 2263-2264). A language becomes dominant when its L1 speakers are more powerful, when the language itself becomes lively, when it is used everywhere, when it becomes a language of market, when it has technical power, and when its culture is popular among the people around the world. When English became a lingua franca among the people involved in different occupation and profession, its popularity and superiority rose up.

\section{Language policy in Nepal}

Language dominance is also affected by language policy of the government. In a multilingual society, language policy determines which language should be promoted and which not, so language dominance starts from the language policy. In the case of Nepal, there are 129 languages out of which only Nepali language has become a dominant language. It has become the national and official language and majority of the population use Nepali as a lingua franca or as second language (Yadav, 2007). Even Nepali language is used as the medium of instruction in Nepal which is regarded as the most dominant language in the case of our context. Language policy is the process of framing language legality to lead them foster. Patten (2001) defines language policy an issue of considerable ethical, political, and legal importance in jurisdictions around the world. Language policy is also guided by political ideology or hegemony, so that policy makers make policy in favour of the language which they want to use. It is not only the case of macro language policy but in the micro level also language policy is influenced by power and hegemony. Fogle and King (2013) focused child as the policy maker. Children use the language which they hear in the school or friend or teachers. Here we can say that language policy is affected by language arbiters (Johnson, 2014) and their ideology.

First language policy was made in 1905 and this policy made Nepali as the language of law and government (Shrestha, 2017). In ancient period, Sanskrit language had superior status. It was the language of academic intellectuals. When the Rana rulers came into power, they did not want to foster nationalistic feeling among the people. Burghart (1984, as cited in Weinberg, 2013) state, "The Rana rulers were not interested in developing the feelings of nationalism that often inspire the imposition of national language policies (p. 63)." When Janga Bahadur Rana 
came into power, he established Durbar High School for Rana family. Though it was for his children, it was the first government-run English medium school in Nepal. When Dev Samsher came into power, he established 200 Nepali language schools to train civil servants. Weinberg (2013) asserts, "Nepali was declared as the official language of education in 1934 (p. 69). Being inspired by Gandhi, Padma Shamsher proposed vernacular schools. Chandra Shamsher established Trichandra College in 1918. It was the first post-secondary educational institution in Nepal. Rai, Rai, Phyak and Rai (2011) state "During Panchayat era (1950-1990), the government, being interested in cultural unification, imposed their political goals through the slogan of 'ek bhasha, ek bhesh, ek dharma, ek desh'[one language, one way of dress, one religion, one nation]." Then, minority languages were completely discouraged. However; each race practised and fostered in the extent they could. They were limited within certain boundary. In1993, a commission was formed to promote national languages and use them in local level even in local administration, primary education and media. This policy let the people run school in mother-tongue and even teach children in their mother-tongue up to primary level. However, people seemed reluctant to educate their children in their mother-tongues. This is due to linguistic power and hegemony.

All the languages of Nepal are equally valued in the constitution. Constitution of Nepal (2015, Article, 6) states that all languages spoken as mother-tongues in Nepal are the languages of the nation. Although all the languages spoken as mothertongues in Nepal have equal status in the constitution, Nepali has been official language, so it has higher status than other languages. However, the concerned federal governments, by a state law, can determine one or more languages of the nation spoken by a majority of the people within the state as its official language(s) in addition to the Nepali language. Similarly, the constitution states that all communities in Nepal have the right of education in their mother-tongues and basic level education will be free and compulsory (Article, 31). It clarifies that minority communities can educate their children in their mother-tongues at primary level. On the other hand, they have to study Nepali language course at grade nine and ten as it is official language all over the country. The students who are expected to be facilitated with the provision of education in their mother-tongues are likely to lag behind because they need extra effort to learn three languages viz. Nepali, English and their mother-tongues. When they have to learn three languages, it is difficult for them to lead all the languages intelligibly and equally. 


\section{Empirical studies}

Several studies explored how hegemony works to influence people in the society. Quite a few of them investigated how dominant language and culture affect the language and culture of minorities and how linguistic hegemony works to influence students' participation in classroom activities.

Xue and Zuo (2013) carried out a research on 'English dominance and its influence on international communication'. The study has found three characteristics of English dominance: the essence of English dominance is the dominance of English speaking countries. This kind of dominance is irresistible and it is hard to be changed in a short time. English dominance is not simply the problem of the globalization of English; it has strong impacts on other aspects of other countries.

Mustapha (2013) carried out a research entitled, 'Linguistic hegemony of the English language in Nigeria'. The purpose of the study was to offer remedies for reported domination of English and its effect on Nigeria's local languages. The study found that there is competition among the local languages especially between the languages of the majority ethnic groups and the languages of the minority ethnic groups. English enters through the chinks while the local languages create them while skirmishing within minor internal conflicts.

Samin (2016) carried out a study entitled, 'Mother tongue hegemony in the state college of Zamboanga Del Sur, Philippines'. The study found that teachers often give priority to the use of English language in classroom understandings, but they often spoke community language to assure sequencing of ideas because they feel easy and comfortable to clarify meaning and promote students' participation on discussions.

Going through these various previously conducted research studies, I found that Xue and Zuo (2013) focused on international communication and Mustapha (2013) prioritized the effect of English in local languages. Samin (2016) conducted his research in Philippines in classroom discussion. As far as I have gone through several research studies, I haven't found any research conducted in language indexicalities in multilingual classrooms in the context of Nepal. Therefore, I thought this area might be more relevant and findings of the study would be more fruitful for teachers to deal with multilingual classes.

\section{Methods and Procedures}

In this study, I used narrative inquiry as a research design. For me, narrative inquiry is a way of understanding experiences in collaboration with participants. 
As it is a process of collaboration involving mutual storytelling and retelling as the research proceeds (Clandinin \& Huber, 2014). I collected Chaudhary students' lived experience, the first-hand experience in their own involvement in everyday events and their stories, the experiences that they got, heard and observed in relation to multilingual English language classrooms. Guba and Lincoln (1964) argue that people are always storytellers; they tell the stories that they live with and/ or around them, the stories my participants provided me will be the main sources of information.

As a research site, I selected Bheemdutta Municipality using non-random purposive sampling procedures. In the same way, school (Shree Mahendranagar Higher Secondary, Sadharan) was also selected using the purposive sampling method. Two Chaudhary students from the sampled schools, who can speak bothNepali and their mother tongue, were sampled using the same sampling procedure considering them as reliable source for my research study. Using semistructured interview, I collected information from them and with their permission, I recorded the interviews which lasted for an hour. I interviewed them three times with the interval of a month and I transcribed the recorded interview and used thematic analysis procedure for making themes from their interview. I derived some global themes from their stories and interpreted them.

\section{Results and Discussion}

For the data collection, I interviewed two students (Bima and Sunil) from Chaudhary community studying in Mahendranagar Higher Secondary school. Collected information were thematized and derived the following themes from their stories for analysis and interpretation.

\section{The enjoyment of learning}

I asked Bima how she felt when he entered in the classroom and she replied:

Sir jab ma class ma aauchhu ani sathi harule wall ma kahile Tharuwa vaner lekhya hunchha. Kahile gaali lekhya hunx. Yekdin "love you moti " bhaaner bhitta ma lekhyathyo. Tyaskaran mero mind le padhai vanda aru ma nai badhi dhyan janchha. Feri ma ghar ko kaam jastai Jandh banauneaadi kaam ma dhyan janchha.

[When I enter the class, I sometimes see 'Tharuwa' sometimes 'Tharu' written on the wall, sometimes, 'I love you fat girl,' sometimes 'vulgar 
words' written on the wall which upsets my mind. And they bring other unnecessary things in my mind rather than the things to study. For example, the moments like making wine and going to sell it occupies my mind and cannot concentrate on what teacher teaches]

From the story of Bima, it can be interpreted that students of minority language community do not enjoy learning English in the classroom. They feel humiliated in the classroom being from so called lower or backward community. Instead of studying they love to work at home and be busy in their households. From my observation of classroom, it can be said that the well managed classroom creates a kind of enthusiasm in learners. Poor classroom management, the language used in the classroom and teacher's behaviour towards them in the classroom are also major factors which demotivates them from coming to school and studying in the classroom. Classroom decoration, furniture and students' sitting clearly proved that they were not enjoying the class.

Instead of study related posters, charts and pictures on the wall to motivate students and concentrate them on study, insulting sentences or vulgar words written on the wall and unnecessary pictures pasted on the wall demotivated students and diverted their minds. Further, the teachers did not seem to have managed sitting and run classroom activities to promote harmony among and between students. During the interview once, Sunil said:

Yek choti ma mero sathi Kiran, jo class second hunthyo uh sang first bench ma base ko the, kinaki aru bench haru paila nai varisakeka thiye. Ani Engl;ish sir aayer vannu vo ; $k$ ho aaj ta yata, padhne man laagyo ki kya ho? Ani tyo din dekhi ma kahile ni agaadi ko bench ma basen.

[Once I was sitting with Kiran, the second topper of our class, on the first bench because there were no seats available in other benches English teacher said, what this is! You are here? Are you really intended to study? From that day I never sat in the first bench]

Furthermore, as Lippman (2010) states Reggio Emilia's view that the physical environment as the 'third teacher' who guides learning, favourable physical environment would help students to concentrate in study but it was not found there. Besides, unfavourable physical environment, pinching linguistic behaviour, inharmonious relationship with teachers and other classmates demoted students particularly those who speak other languages - the languages other than the medium of instruction as their first language. 


\section{Classroom motivation}

Motivation plays a vital role to encourage students to participate in classroom activities and perform their roles more actively. The students who got sufficient motivation and those who were self motivated despite many discouraging factors progress significantly. But the students who are not supported, encouraged, and appreciated by teachers, parents, friends and other concerned people and are unable to be self-motivated are found to feel being ignored and isolated. The fact is that the more active the students become the more they learn, the less active the students become, the less they learn, the easier for the teacher, the cheaper and better support for the parents. It is clear from Sunil's voice:

Sir yadi hami haru le badhi padhyau ra sir lai badhi question garyau vane aru students haru le achamma manchhan. Hamilai kahile kahi sir le k vannu vayoyo vaner tha hudain ani nepali ma sodhyo vane sathi haru haschhan class ma, mero nepali tyati ramro chhaina ni tyei vayer, Tyaskaran ma class ma khasai boldain nabujhe ni basi rakhchhu.

[If we study more, it will be a surprise for teachers; we will have more questions to ask to teachers. We do not understand exactly what teacher says in English and when we ask teacher in Nepali than all students laugh due to my Nepali language. Therefore I do not speak in the class even if I do not understand the content.]

This means in the classroom also minority language community students were neglected and when they spoke Nepali, then they were made fun because of their accent. They found it difficult to speak in the classroom even in Nepali. Therefore, they hesitate to participate in any kind of activities in the classroom. This can be said that Gramscian theory of hegemony can be reflected in this class. Sunil also said that:

Hamilai respect garer boln ni aaudain, yek din maile sir timile vaneko bujhen vanda tyo sir le malai kutnu vo kin ki maile tapai vane thau ma timi vanexu" Ani tyo din dekhi maile tyo sir lai kahile pani question sodhen.

[We sometimes do not know which word is honorific and which not. One day I used non-honorific word with my teacher and I got beaten by my teacher. From that day I never asked question to him].

This can be seen that how language dominance hampers their learning activities. Therefore, teacher should be very cautious while dealing with students in multilingual classrooms. Teachers should motivate them for studying intrinsically or extrinsically. 


\section{Linguistic dominance}

Language is a tool to create power. The students who can speak confidently in the classroom seem more powerful than those who hesitate to speak nonstandard variety and dominated languages. Van Dijk (1993) believes that the elites dominate others with the power of wealth, income, position, status, force, group membership, education or knowledge which is socially valued resources. Students with socially valued recourses have higher status, better confidence and less likely to feel nervousness. This status has encouraged them to perform better in academic excellence.

In the classroom interaction when we ask students to answer the question, the students who feel being superior speak confidently without any hesitation and shyness but those who have a feeling of being inferior hesitated to speak and use substandard variety of language. Powerless forms of language are hedges, intensifiers, tag questions, hesitations, deictic phrases, and polite forms (Bustrum, 2001). These forms of language are more likely to be observed in those of low social status people. In English language classrooms, it was found in the students whose mother-tongue was different from the medium of instruction. During the interview Bimu said:

Sir hami haru lai farar angreji aaudain ani bolda kheri sochdai boldai garnu parchha bich bich ma naaaye pachhi hamro bhasa ni use garidinchhau ani hamilai laaz lagchha

[Sir, we cannot speak English fluently so that we keep pause while speaking and use sometimes mother tongue if we do not know exact word in English. When we use our mother tongue in the classroom we feel shy or hesitation.]

The story of Bimu can be related with Bustrum's (2001) theory of language power. He has mentioned the sources of power from which people can be influenced. They are reward power (the ability to give), coercive power (the ability to punish), legitimate power (the ability to influence), referent power (the need of the referent to identify with the speaker), and expert power (the ability to provide information). Both the people and students from minority community particularly from Chaudhary community are less likely to possess any of these sources of power. This emptiness of power led them to feel inferior to those who possess these sources of power.

Teachers use power in different ways. Bustrum (2001) has described how teachers use power in English language classroom. Russian teachers 'speak loudly and yell' using commands such as "keep quiet!" Many of Korean teachers use nonverbal and corporal punishment to demonstrate their power. In Sudan, Judan and 
Amani, teachers never speak loudly and harshly to their students. In Ethiopia and Bosnia teachers do not raise their voice volume or get angry while dealing with students. In Nepal, teachers are discouraged to use physical punishment. They are trained, taught and advised to apply psychological treatment as punishment and completely avoid corporal punishment. Teachers were found to have treated students saying some satirical words, ignoring them, staring angrily, or by asking questions. However, students seemed to have asked questions when they did not understand what the teacher taught. Once, Sunil expressed his feelings of dominated by his class teacher:

Yek din ma school ma alikati late puge ani sir chahi pahile nai gai saknu vayeko rahex. maile sir lai May I come in sir vanda uha le malai vannu vo ki "Ka bathin aaitho re machhi maran gaitho" ani sabai students hase ani malai kasto laaz lagyo tyo din pani.

[One day I came late in my class and asked to my teacher to come in, instead of letting me come in he used my mother tongue and dominated me as if I came from fishing. I felt very humiliated at that time.]

The words, phrases or sentences teachers used as a punishment in the classroom have dominant influences. When I asked them in which bench they used to sit in the class, they replied on the fifth or sometimes last (sixth) bench not on the first or second bench because teachers used to ask questions to those who used to sit on these benches. Sunil added, "Hami jandaina, homework pani garna bhyaudaina [We cannot answer, do not have time to do homework]. In the question asked what they did when they did not understand what teachers taught, they replied they used to ask their friends and used to be afraid of asking teachers. In case of punishment, they said that they used to address them with very pinching words like kasto murkh student hola yatti ni najanne! [What a stupid student], machhi marn jaitho fir, [Want to go fishing then?]. They use our language as dominating and harassing language in the classroom. They do not allow us to speak in our language in the school and our friends also laugh at us when we speak our language in the class. Sunil said, Tini haru haschhan hamro bhasa bolyo vane ani hamilai laaz lagch ani najaner ni Nepali nai bolnu parch. [Our friends laugh at us when we use our language and we feel humiliation and switch our language into Nepali even if we don't know Nepali language clearly]. When I saw some sort of reluctance in students to participate enthusiastically in classroom activities, I moved ahead to explore the role of motivation in them. In order to detect what the students actually wanted in their classroom, I, being in the school for a week, observed the environment of the school 
being a part of the school family; I went to the leisure class, played with the students, and had snacks in the school canteen where students also used to have. Involving in different activities with the students, I tried to dig out the role of their mother tongue in their study. I found them feeling quite struggling to communicate in Nepali language because most of the time they use their mother tongue at home and in their community. Dailey (2009) states that integratively motivated students are more successful at learning an L2 than instrumentally motivated ones. So it was not found in my research site. They were found demotivated by their peer or even teachers in the classroom.

\section{Conclusion}

This study tried to explore the feelings and experiences of minority language group students while studying in multilingual classrooms focusing the case of Chaudhary language. The study was carried out in Kanchanpur district using narrative inquiry as a research design. Two participants from chaudhary community were selected using purposive sampling technique and they were interviewed for an hour each time. The collected data were transcribed and derived themes from their responses. I mainly derived three themes from the collected data and analyzed them qualitatively. The findings of this study indicate that learners from minority communities like Chaudhary experienced the linguistic dominance in English language classrooms. Stories of the participants in this study show that students feel and experience dominance in English language classroom and they do not enjoy in the classroom. Sometimes dominance is implicit and sometimes it is explicit. No child feels superior or inferior by birth. They feel and experience it later as they get involved in different activities and come in touch with different people in the society. However, it begins from their family and pervades with their contact with others. This can be clearly seen in this study from the experiences of the participants. They feel demotivated in the classroom from their peer and even sometimes from their teachers too. Demotivated learners cannot progress in their study and express negative attitudes towards learning in a particular situation. They feel inferiority complex in the classroom due to linguistic deficiency in the dominant language. Learners feel humiliated using their language in classroom that creates great problem in their study because they are never interested to take part in classroom discussion feeling dominated due to linguistic deficiency.

I tried to make my study more representative including students from other languages too but due to some time constraints I could not involve them in my study. Similarly, I was unable to observe their classes to find out whether the participants of 
the study were telling true or not. So for getting more clarity in language indexicality further research can be conducted in the same area involving students from other minority groups. Superficial observation of classes and listening to their stories only may not clearly unpack the realities of the classroom, so that further researchers should also deeply observe their classes and have ethnographic studies to get the real scenario.

Finally, from the findings of this research, it can be concluded that using a dominant language in the classroom is problematic for those students whose mother tongue is different from the standard or dominant language. In such condition a teacher should be quite conscious about language use and should encourage them to involve in classroom interaction even using their mother tongue. Teachers should make sure whether students are enjoying their class or not, whether their words are dominating others or not.

\section{References}

Bates, T. R. (2010). Gramsci and the theory of hegemony author(s). Journal of the History of Ideas, 36(2), 351-366. Retrieved from http://www.jstor.org/stable 12708933.

Blommaert, J. (2010). The sociolinguistics of globalization. London: Cambridge University Press.

Central Bureau of Statistics. (2011). National population and housing census. Kathmandu.

Clandinin, D. J., \& Huber, J. (2014). Narrative inquiry. In McGaw, B., Baker, E. \& Peterson (Eds.), International encyclopedia of education ( $3^{\text {rd }}$ ed.). New York, NY: Elsevier.

Crystal, D. (2003). English as a global language. London: Cambridge University Press.

Dailey, A. (2009). Key motivational factors and how teachers can encourage motivation in their students. Retrieved from https://www.birmingham. ac.uk/.../DailySLAKeyMotivationalFactorsandHowTeachers

Gramsci, A. (1971). Selections from the prison notebooks. Hoare, Q. \& Smith, G.N. (Trans \& Eds.).New York, NY: International Publisher.

Guba, E. G., \& Lincoln, Y. (1994). Competing paradigms in qualitative research. In Denzin, N. K \& Lincoln, Y.S. (eds.), Handbook of qualitative research. Thousand Oaks, CA: Sage Publications. 
Haberland, H. \& Mortensen, J. (2012). Language variety, language hierarchy and language choice in the international university. International Journal of Sociology of Language. Retrieved from: https://doi.org/10.1515/ijsl-20120036

Jiang, Z. (2011). A research and counter-measures of English cultural hegemony in China. Asian Social Association, 7(1), 194-200.

Johnson, D.C., \& Johnson, E.J. (2015). Power and agency in language policy appropriation. Language Policy, 14, 221-243.

Maum, R. (2002). Nonnative-English-speaking teachers in the English teaching profession. JCPS Adult and Continuing Education, 2(9), 202-362.

Mustapha, A. S. (2013).Gender and language education research: A review. Journal of Language Teaching and Research,4(3), 454-463.

National Education Commission Report. (1993). Government of Nepal. Kathmandu: Authors.

Patten, A. (2001). Political theory and language policy. Retrieved from: https:// www.princeton.edu/ apatten/languagepolicy_politicaltheory.pdf

Poudel, P. (2010). Teaching English in multilingual classrooms of higher education: The present scenario 2010. Journal of NELTA, 15(1-2).

Rai, V.S., Rai, M., Phyak, P. \&, Rai, N. (2011). Multilingual education in Nepal: Hearsay and reality? A Report Paper Commissioned for UNESCO. Kathmandu: UNESCO.

Romaine, S. (2002). The impact of language policy on endangered languages. International Journal on Multilingual Societies, 4(2), 1564-4901.

Spencer-Oatey, H. (2012). What is culture? A compilation of quotations. Global pad core concepts. Global pad open house. Retrieved from: http://www.warwick. ac.uk/globalpadintercultural

Suarez, D. (2002). The paradox of linguistic hegemony and the maintenance of Spanish as a heritage language in the United States. Retrieved from: http:// www.u.arizona.edu/ rgolden/Hegemony.pdf

Weinberg, M. (2013). Revisiting history in language policy: The case of medium of instruction in Nepal. Working Papers in Educational Linguistics (WPEL), 28 (1), 61-80.

Xue, J., \& Zuo, W. (2013). English domination and its influence on international communication. Theory and Practice in Language Studies, 3(12), 2262-2266.

Young, P. A. (2008).The culture based mode: Constructing a model of culture. Educational Technology \& Society, 11(2), 107-118. 